\title{
QUALIDADE DE GRÃOS DE ONZE CULTIVARES DE SOJA
}

\author{
BRUNINI, Maria Amalia ${ }^{1}$ \\ BARROS, Mateus Aguiar de Lima ${ }^{2}$ \\ PEREIRA, Marcio ${ }^{3}$ \\ CERQUEIRA, Junior Barrachi ${ }^{4}$ \\ MENEZES, Pamella T. Rochiski ${ }^{4}$ \\ FURTADO, Irving Ramos ${ }^{4}$
}

SUMMARY: Este trabalho teve como objetivo avaliar o teor de óleo, proteína bruta e minerais (N, P, K, Ca, Mg, $\mathrm{S}, \mathrm{Cu}, \mathrm{Fe}, \mathrm{Zn}$ ), em grãos de onze cultivares de soja, oriundas da cidade de Ituverava, Estado de São Paulo, Brasil. As cultivares de soja estudadas foram 5G685, 97Y07, 97R21, 6563RFS IPRO, 7062 IPRO, 7062 IPRO, 6663RFS BRAMAX, 1360CIPRO, 13610 IPRO, AS3730, 97Y21, 1366C IPRO. Pelos resultados obtidos pode-se concluir que, as cultivares de soja aqui estudadas, apresentaram alto teores em óleo e baixo teor de proteína, comparado com os valores citados na literatura. No geral, pode-se concluir que, através dos resultados obtidos neste estudo, as cultivares de soja, aqui estudadas, tem potencial para utilização na alimentação humana ou animal, e com relação ao teor de óleo, todas as cultivares são promissoras para a indústria de extração de óleo.

Palavras-chave: Glycine max (L.) Merrill. Óleo. Proteína. Minerais

SUMMARY: The objective of this work was to evaluate the oil, protein and minerals (N, P, K, Ca, Mg, S, Cu, Fe, $\mathrm{Zn})$ contents in grain of eleven soybean cultivars, from Ituverava city, San Paulo state, Brazil . The soybean cultivars studied were 5G685, 97Y07, 97R21, 6563RFS IPRO, 7062 IPRO, 7062 IPRO, 6663RFS BRAMAX, 1360CIPRO, 13610 IPRO, AS3730, 97Y21, 1366C IPRO. From the results obtained, it can be concluded that the soybean cultivars studied here presented high levels of oil and low protein content, compared to the values reported in the literature. In general, it can be concluded that through the results obtained in this study, the soybean cultivars have potential for use in human or animal food, and in relation of the oil content, all cultivars are promising for the oil extraction industry

Keywords: Clycine Max (L.) Merril. Oil. Protein. Minerals.

\section{INTRODUÇÃO}

A soja [Glycine $\max (\mathrm{L}$.$) Merrill] é originária do continente Asiático, mais precisamente,$ da China, de onde se difundiu para a Europa em 1712 e para o Brasil em 1882 (QUEIRÓZ et al. apud ALMEIDA et al., 2016). Atualmente, é um dos produtos agrícolas, mundialmente, mais comercializados, provavelmente, devido às suas diversas formas de consumo, que vão desde a

\footnotetext{
${ }^{1}$ Professora Livre-docente e Doutora Aposentada da Faculdade de Ciências Agrárias e Veterinárias/UNESP, Campus de Jaboticabal e Professora Doutora da Fundação Educacional de Ituverava, Rua Coronel Flauzino Barbosa Sandoval, 1259, Ituverava-SP, CEP=14500-000.E-mail: brunini@ feituverava.com.br; amaliabrunini@gmail.com

${ }_{2}$ Engenheiro Agrônomo formado pela Faculdade Dr. Francisco Maeda, Fundação Educacional de Ituverava. Rodovia Jerônimo Nunes Macedo, Km 05, Ituverava-SP, CEP=14500-000. E-mail: mateus.aguiarlb@ gmail.com

3 Professor Doutor da Fundação Educacional de Ituverava, Rua Coronel Flauzino Barbosa Sandoval, 1259, Ituverava-SP, CEP=14500-000. E-mail: marciopereira@ feituverava.com.br

${ }^{4}$ Acadêmicos da Faculdade Dr. Francisco Maeda-FAFRAM/FE. Rodovia Jerônimo Nunes Macedo, Km. 01, Ituverava-SP, CEP=14500-000.
} 
alimentação humana e animal, até indústrias farmacêuticas e siderúrgicas (SBARDELOTTO; LEANDRO, 2008).

O Brasil se tornou o segundo maior produtor e o maior exportador de soja mundial (AGRIANUAL, 2015), e segundo Cavalcante (2011), a soja é considerada uma das culturas mais importantes do Brasil, devido sua composição em óleo e proteína vegetal.

Martin et al. (2005), cita que, a ascensão da soja no Brasil é devido, principalmente, ao setor da pesquisa, que apresenta inovações técnicas e científicas, proporcionando ao produtor rural novas cultivares de soja produtivas e resistentes, que ocasionam menor custo da produção. De acordo com o Registro Nacional de Cultivares do Ministério da Agricultura e Abastecimento, existem mais de 1200 cultivares de soja no Brasil (MAPA, 2016).

As diferentes cultivares de soja existentes no mercado apresentam diferença em sua composição, a qual, de acordo com Demborguski (2003) é função dos percentuais de óleo, proteína, umidade, carboidratos, fibras e cinzas. Segundo Albrecht et al. (2008), os teores de óleo e proteína estão relacionados ao melhoramento genético e durante o período de enchimento dos grãos ao ambiente de cultivo como clima, solo, temperatura e precipitação pluviométrica.

Em termos de composição química, cerca de $60 \%$ do peso seco do grão é constituído de óleo e proteína, com média $40 \%$ de proteína, $20 \%$ de óleo, 35\% de carboidratos e 5\% de fibras (POYSA et al., 2006). A correlação entre o teor de proteína e de óleos é considerada negativa, pois a medida que aumenta o teor de proteína, o teor de óleo é reduzido e vice-versa (MORAES et al., 2006). A soja também é rica em minerais os quais estão na forma de micronutrientes e macronutrientes (EMBRAPA, 2016).

De acordo com a Tabela de composição química dos alimentos do NEPA/UNICAMP (2011), a composição da farinha de soja por 100 gramas de parte comestível é de 2,87mg de manganês, 539mg de fósforo, 13,1mg de ferro, 6mg de sódio, 1922mg de potássio, 1,29mg de cobre, 4,5mg de zinco, 242mg de magnésio, 36g de proteína e 14,6g de lipídeos.

Considerando o potencial tecnológico produtivo de grãos de soja, a sua utilização tanto na alimentação humana quanto animal, e que o conhecimento dos componentes de um vegetal sempre é a etapa inicial na determinação de suas potencialidades industriais e alimentícias, este trabalho objetivou avaliar os teores de proteína, óleo e alguns minerais em grãos de diferentes cultivares de soja oriundas do município de Ituverava/SP.

\section{MATERIAL E MÉTODOS}

Foram avaliados grãos de 11 cultivares de soja oriundas da cidades de Ituverava, estado de São Paulo, Brasil. Os grãos de soja das cultivares 5G685, 97Y07, 97R21, 6563RFS 
IPRO, 7062 IPRO, 7062 IPRO, 6663RFS BRAMAX, 1360CIPRO, 13610 IPRO, AS3730, 97Y21, 1366C IPRO, foram estudados neste estudo. Teve-se cuidado de analisar somente grãos de soja, colhidos durante a safra 2014/2015. Os grãos de cada cultivar, após escolha e seleção cuidadosa, foram lavados conforme o recomendado por Sarruge; Haag (1974), e em seguida, seco ao ar por, aproximadamente, 24 horas. Em seguida os grãos foram macerados em trituradores domésticos e a farinha integral obtida foi utilizada para determinação de proteína, óleo e alguns minerais. A amostra, de cada cultivar, foi dividida em duas sub amostras, sendo a primeira utilizada para a extração do óleo no Laboratório de Fisiologia Pós-colheita de Frutas e Hortaliças da Faculdade Doutor Francisco Maeda - FAFRAM/FE e a segunda, encaminhada ao Laboratório de Solos e Análise Foliar, também, da FAFRAM/FE para a determinação dos minerais, nitrogênio $(\mathrm{N})$, fósforo $(\mathrm{P})$, potássio $(\mathrm{K})$, cálcio $(\mathrm{Ca})$, magnésio $(\mathrm{Mg})$, enxofre $(\mathrm{S})$, cobre $(\mathrm{Cu})$, ferro $(\mathrm{Fe})$ e zinco $(\mathrm{Zn})$.

A determinação do teor de lipídeos totais (óleo) foi realizada com auxilio de extrator Soxhlet, utilizando éter de petróleo como solvente, de acordo com os procedimentos descritos nas normas analíticas do INSTITUTO ADOLFO LUTZ (IAL, 2008), com refluxo de 7 a 8 horas, e o resultado expresso em porcentagem (\%).

A determinação de nitrogênio foi realizada pelo método de Kjeldahl, conforme recomendação de Malavolta et al. (1997), com ligeiras modificações, e o teor expresso em g. $100 \mathrm{~g}^{-1}$ de soja. Na determinação dos minerais K, Ca, Mg, S, Cu, Fe e Zn, o Laboratório de Química da FAFRAM/FE utiliza Espectrofotômetro de Absorção Atômica da Perkim Elmer modelo analist 100, e na determinação de fósforo (P) e Enxofre (S), utiliza o método fotométrico, através do uso do Espectrofotômetro modelo 600 PLUS da FEMTO. A digestão das amostras utilizadas nas determinações dos minerais é a nitro-perclórica, conforme recomendação de Malavolta et al. (1997).

A partir do teor de nitrogênio total foi calculado o teor de proteína total, na soja triturada, utilizando o fator 6,25, conforme descrito por Albrecht et al. (2008) e Silva (2002). O teor foi expresso em g. $100 \mathrm{~g}^{-1}$ de soja.

O experimento foi realizado em delineamento inteiramente casualizado com onze tratamentos (cultivares) e cinco repetições. Os dados obtidos foram submetidos à análise de variância comparando as médias obtidas através do teste de Tukey, a nível de 5\% de probabilidade, utilizando-se o programa computacional ASSISTAT (SILVA, 2015).

\section{RESULTADOS E DISCUSSÃO}

A Tabela 1 mostra os resultados obtidos quanto aos teores de proteína bruta e de óleo 
nas diferentes cultivares de soja estudadas nesse trabalho, onde pode-se observar, que ocorreu variação tanto nos teores de óleo como nos de proteína bruta, em função das cultivares.

Quanto ao teor de óleo, as cultivares AS 3730 e 13610 IPRO foram as que apresentaram os menores valores, respectivamente, $20,63 \%$ e $21,47 \%$. Este comportamento é coerente com a citação de Moraes et al. (2006) de que a correlação entre teor de proteína e de óleo é negativa, pois a medida que o teor de proteína aumenta, o teor de óleo é reduzido.

Tabela 1 - Proteína bruta, expressa em g. $100 \mathrm{~g}^{-1}$, e óleo, expresso em porcentagem, em em grãos de diferentes cultivares de soja. Ituverava, 2015.

\begin{tabular}{|c|c|c|}
\hline \multirow[t]{2}{*}{ Cultivares } & \multicolumn{2}{|c|}{ Farinha integral } \\
\hline & $\begin{array}{l}\text { Proteína bruta } \\
\quad\left(\mathrm{g}^{\left.100 \mathrm{~g}^{-1}\right)}\right.\end{array}$ & $\begin{array}{c}\text { Teor de óleo } \\
(\%)\end{array}$ \\
\hline $5 \mathrm{G} 685$ & $34,33 \mathrm{abc}$ & $23,38 \mathrm{abc}$ \\
\hline 97Y07 & $34,12 \mathrm{abc}$ & $23,46 \mathrm{ab}$ \\
\hline 97R21 & $34,20 \mathrm{abc}$ & $22,55 \mathrm{bcd}$ \\
\hline 6563 RFS IPRO & $33,21 b c$ & $24,04 \mathrm{a}$ \\
\hline 7062 IPRO & $32,75 c$ & $22,53 \mathrm{de}$ \\
\hline 6663 RFS BRAMAX & $33,92 \mathrm{abc}$ & $21,54 \mathrm{de}$ \\
\hline 1360 CIPRO & $35,56 \mathrm{a}$ & $21,47 \mathrm{de}$ \\
\hline 13610 IPRO & $33,21 b c$ & $20,63 \mathrm{e}$ \\
\hline AS 3730 & $35,57 \mathrm{a}$ & $22,57 \mathrm{bcd}$ \\
\hline $97 Y 21$ & $34,00 \mathrm{abc}$ & $22,39 \mathrm{bcd}$ \\
\hline 1366C IPRO & $34,77 \mathrm{ab}$ & $22,53 \mathrm{de}$ \\
\hline $\mathrm{dms}^{(1)}$ & 1,90689 & 1,29777 \\
\hline $\mathrm{F}^{(1)}$ & $5,7687 * *$ & $16,1131 * *$ \\
\hline $\operatorname{cv} .(\%)^{(1)}$ & 1,91 & 1,98 \\
\hline $\mathrm{mg}^{(1)}$ & 34,15 & 22,51 \\
\hline
\end{tabular}

Fonte: Elaborada pelos autores

Com relação à concentração de proteína bruta obtida nas amostras das diferentes cultivares de soja, através dos dados apresentados na Tabela 1, pode-se verificar que diferiram estatisticamente, e que o menor valor foi encontrado no grão de soja da cultivar 7062 IPRO $\left(32,75.100 \mathrm{~g}^{-1}\right)$, e o maior no cultivar AS $3730\left(35,57 \mathrm{~g} \cdot 100 \mathrm{~g}^{-1}\right)$. Os valores de proteínas totais encontrados nas diferentes cultivares de soja, aqui estudadas, variaram de 32,75 a 35,56 g. $100 \mathrm{~g}^{-1}$, valores estes coerentes aos obtidos por Marega Filho et al. (2001) que é de 32,95 a 41,56\%.

Comparando os valores aqui obtidos, com os encontrados por Vieira et al. (1999), em estudo de seis cultivares de soja (IAS-4, EMBRAPA-4, Davis, BR-16, Iguaçu e IAS-5), que foram de $23,8 \%$ a $28,24 \%$ de óleo e $38,56 \%$ a $41,95 \%$ de proteína, pode-se concluir que são inferiores, tanto para óleo quanto para proteína. 
Comparando os resultados obtidos neste estudo, com os citados na tabela de composição química da NEPA/UNICAMP (2011), verifica-se que o teor de proteína está abaixo do citado que é de $36 \mathrm{~g} \cdot 100 \mathrm{~g}^{-1}$.

Com relação aos teores de macronutrientes $\mathrm{N}, \mathrm{P}, \mathrm{K}, \mathrm{Ca}, \mathrm{Mg}$ e S obtidos nas diferentes cultivares, através dos dados apresentados na Tabela 2, pode-se observar que ocorreu ligeira diferença estatística. De acordo com a Tabela de Composição química da NEPA/UNICAMP (2011) a composição mineral de farinha de soja é de 242mg de magnésio, 2,87mg de manganês, 539mg de fósforo, 13,1mg de ferro, 1922mg de potássio, 1,29mg de cobre e 4,5mg de zinco, e neste estudo, através da Tabela 2, pode-se verificar que os valores encontrados para magnésio $(\mathrm{Mg})$ foram superiores, enquanto que os valores de $\mathrm{P}, \mathrm{K}$, aqui obtidos, são coerentes, pois o teor de $\mathrm{P}$ variou de 0,53 a $0,57 \mathrm{~g} .100 \mathrm{~g}^{-1}$, o de $\mathrm{K}$ de 1,70 a $1,85 \mathrm{~g} .100 \mathrm{~g}^{-1}$.

Tabela 2 - Macronutrientes (N, P, K, Ca, Mg e S) em grãos de diferentes cultivares de soja. Ituverava 2016.

\begin{tabular}{|c|c|c|c|c|c|c|}
\hline \multirow[b]{2}{*}{ Cultivares } & \multicolumn{6}{|c|}{ Minerais $\left(\mathrm{g.100g}^{-1}\right)$} \\
\hline & $\mathbf{N}$ & $\mathbf{P}$ & $\mathbf{K}$ & $\mathbf{C a}$ & $\mathrm{Mg}$ & $\mathbf{S}$ \\
\hline 5 G685 & $5,49 \mathrm{abc}$ & $0,57 \mathrm{ab}$ & $1,84 \mathrm{ab}$ & $0,22 d$ & $0,28 \mathrm{ab}$ & $0,22 \mathrm{de}$ \\
\hline 97Y07 & $5,46 a b c$ & $0,57 \mathrm{a}$ & $1,70 \mathrm{ab}$ & $0,23 \mathrm{~cd}$ & $0,28 \mathrm{ab}$ & $0,21 \mathrm{e}$ \\
\hline 97R21 & $5,42 \mathrm{abc}$ & $0,57 \mathrm{ab}$ & $1,72 \mathrm{ab}$ & $0,25 \mathrm{abc}$ & $0,31 \mathrm{a}$ & $0,30 \mathrm{a}$ \\
\hline 6563RFS IPRO & $5,31 b c$ & $0,56 \mathrm{abc}$ & $1,83 \mathrm{ab}$ & $0,25 \mathrm{abc}$ & $0,29 \mathrm{ab}$ & $0,28 \mathrm{ab}$ \\
\hline 7062 IPRO & $5,24 \mathrm{c}$ & 0,55 bcde & $1,84 \mathrm{ab}$ & $0,24 \mathrm{bcd}$ & $0,26 b c$ & $0,28 \mathrm{ab}$ \\
\hline 6663RFS BRAMAX & $5,49 \mathrm{abc}$ & $0,54 \mathrm{cde}$ & $1,80 \mathrm{ab}$ & $0,24 \mathrm{bcd}$ & $0,29 \mathrm{ab}$ & $0,27 \mathrm{ab}$ \\
\hline 1360C IPRO & $5,69 \mathrm{a}$ & $0,54 \mathrm{de}$ & $1,64 b$ & $0,24 \mathrm{bcd}$ & $0,29 \mathrm{ab}$ & $0,27 \mathrm{abc}$ \\
\hline 13610 IPRO & $5,31 b c$ & $0,54 \mathrm{cde}$ & $1,94 \mathrm{a}$ & $0,22 \mathrm{~d}$ & $0,27 b$ & $0,21 \mathrm{e}$ \\
\hline AS 3730 & $5,69 \mathrm{a}$ & $0,53 \mathrm{e}$ & $1,73 \mathrm{ab}$ & $0,23 \mathrm{~cd}$ & $0,23 c$ & $0,24 \mathrm{~cd}$ \\
\hline $97 Y 21$ & $5,46 a b c$ & $0,54 \mathrm{cde}$ & $1,85 \mathrm{ab}$ & $0,26 a b$ & $0,23 c$ & $0,22 \mathrm{de}$ \\
\hline 1366C IPRO & $5,56 \mathrm{ab}$ & $0,56 a b c d$ & $1,83 \mathrm{ab}$ & $0,27 \mathrm{a}$ & $0,31 \mathrm{a}$ & $0,26 \mathrm{bc}$ \\
\hline $\mathrm{dms}^{(1)}$ & 0,31824 & 0,02272 & 0,28975 & 0,2919 & 0,03903 & 0,03006 \\
\hline $\mathrm{F}^{(1)}$ & $5,3295^{* *}$ & $10,5600 * *$ & $2,2408 \mathrm{~ns}$ & $8,4545^{* *}$ & $12,7322 * *$ & $29,108 * *$ \\
\hline cv.(\%) ${ }^{(1)}$ & 1,99 & 1,41 & 5,53 & 4,12 & 4,83 & 4,08 \\
\hline $\mathrm{mg}^{(1)}$ & 5,47 & 0,5533 & 1,79455 & 0,24273 & 0,03903 & 0,25242 \\
\hline
\end{tabular}

(1) $\mathrm{dms}=$ diferença mínima significativa para comparação das médias pelo teste de Tukey; s= desvio padrão das medias; c.v=coeficiente de variação em porcentagem; F: * significativo a 5\% de nível de probabilidade, **= significativo a $1 \%$ de nível de probabilidade;

Médias seguidas de letras iguais nas colunas não diferem entre si, pelo teste Tukey, a 5\% de probabilidade. Fonte: Elaborada pelos autore

O valor de cálcio obtido, variou de 0,22 a $0,27 \mathrm{~g} \cdot 100^{-1}$, e são superiores aos obtidos por Panero et al. (2007) em 5 cultivares de soja (BRS Raimunda, Serena, Embrapa 63 Mirador, BRS Luziânia e BRS MG Nova Fronteira) do estado de Roraima, pois o mesmo obteve variação de 37,8 a $101,7 \mathrm{mg}_{\mathrm{kg}}{ }^{-1}$. Os valores aqui obtidos para os minerais $\mathrm{Ca}, \mathrm{Mg}, \mathrm{K}$ (Tabela 2) são coerentes aos obtidos por Kamizake et al. (2006) em cultivares de soja, que foram de 0,20 a 0,37 g. $100 \mathrm{~g}^{-1}$ de Ca, 0,22 a 0,26 g. $100 \mathrm{~g}^{-1}$ de $\mathrm{Mg}$ e 1,93 a 2,02 g. $100 \mathrm{~g}^{-1}$ de K. 
Quanto aos teores dos micronutrientes $\mathrm{Cu}, \mathrm{Fe}, \mathrm{Mn}$ e $\mathrm{Zn}$ obtidos neste estudo, pode-se verificar pelos dados da Tabela 3 que ocorreu pequena variação entre as diferentes cultivares, com exceção aos valores encontrados para o teor de ferro (Fe).

Tabela 3: $\mathrm{Cu}, \mathrm{Fe}, \mathrm{Mn}$ e Zn em grãos de diferentes cultivares de soja. Ituverava 2016.

\begin{tabular}{|c|c|c|c|c|}
\hline \multirow[b]{2}{*}{ Cultivares } & \multicolumn{4}{|c|}{ Minerais (mg.100g ${ }^{-1}$ ) } \\
\hline & $\mathrm{Cu}$ & $\mathrm{Fe}$ & $\mathrm{Mn}$ & $\mathrm{Zn}$ \\
\hline $5 \mathrm{G} 685$ & $1,36 \mathrm{a}$ & $11,60 \mathrm{bcd}$ & $2,43 a b$ & $3,33 b c$ \\
\hline 97Y07 & $1,20 \mathrm{ab}$ & $11,40 \mathrm{bcd}$ & $2,23 b c$ & $3,23 \mathrm{c}$ \\
\hline 97R21 & $1,13 \mathrm{ab}$ & $11,10 \mathrm{~cd}$ & $2,23 b c$ & $3,23 \mathrm{c}$ \\
\hline 6563RFS IPRO & $1,00 \mathrm{~b}$ & $10,75 \mathrm{~cd}$ & $2,40 \mathrm{abc}$ & $3,40 \mathrm{bc}$ \\
\hline 7062 IPRO & $1,10 \mathrm{~b}$ & $16,23 \mathrm{a}$ & $2,26 a b c$ & $3,83 \mathrm{a}$ \\
\hline 6663 RFS BRAMAX & $1,13 \mathrm{ab}$ & $12,46 \mathrm{~b}$ & $2,50 \mathrm{ab}$ & $3,80 \mathrm{a}$ \\
\hline 1360CIPRO & $1,20 \mathrm{ab}$ & $10,60 \mathrm{~cd}$ & $2,40 \mathrm{abc}$ & $3,30 \mathrm{bc}$ \\
\hline 13610 IPRO & $1,20 \mathrm{ab}$ & $10,43 d$ & $2,10 \mathrm{c}$ & $3,26 \mathrm{c}$ \\
\hline AS3730 & $1,20 \mathrm{ab}$ & $10,63 \mathrm{~cd}$ & $2,23 b c$ & $2,76 b$ \\
\hline $97 Y 21$ & $1,10 b$ & $11,86 b c$ & $2,30 \mathrm{abc}$ & $3,63 \mathrm{ab}$ \\
\hline 1366C IPRO & $1,20 \mathrm{ab}$ & $10,53 \mathrm{~cd}$ & $2,56 \mathrm{a}$ & $3,53 \mathrm{abc}$ \\
\hline $\mathrm{dms}^{(1)}$ & 0,2491 & 1,35266 & 0,30486 & 0,33703 \\
\hline$F^{(1)}$ & $3,4833 * *$ & $38,7421 * *$ & $5,2556^{* *}$ & $20,4409 * *$ \\
\hline $\mathrm{cv} .(\%)^{(1)}$ & 7,31 & 3,99 & 4,48 & 3,40 \\
\hline $\mathrm{mg}^{(1)}$ & 1,16667 & 11,60152 & 2,33333 & 3,39394 \\
\hline
\end{tabular}

(1) $\mathrm{dms}=$ diferença mínima significativa para comparação das médias pelo teste de Tukey; $\mathrm{s}=$ desvio padrão das medias; c.v=coeficiente de variação em porcentagem; F: *= significativo a 5\% de nível de probabilidade, **= significativo a $1 \%$ de nível de probabilidade; Médias seguidas de letras iguais nas colunas não diferem entre si, pelo teste Tukey, a 5\% de probabilidade.

Os valores encontrados para ferro neste estudo variaram de 10,43 a $16,23 \mathrm{mg} \cdot 100 \mathrm{~g}^{-1}$ e são coerentes ao valor citado por Ciabott et al. (2005) que é de 7,900 a 13,038mg $.100 \mathrm{~g}^{-1}$, com exceção ao valor obtido pela cultivar 7062 IPRO, que foi de $16,23 \mathrm{mg} .100 \mathrm{~g}^{-1}$.

Comparando os resultados aqui obtidos para os minerais $\mathrm{Cu}, \mathrm{Mn}$ e Fe (Tabela 3) com os obtidos por Kamizake et al. (2006) em cultivares de soja (EMBR-59, BRS-133 e BRS-137), que foram 1,30 a $1,57 \mathrm{mg} \cdot 100 \mathrm{~g}^{-1} \mathrm{de} \mathrm{Cu}, 2,83$ a $3,25 \mathrm{mg} \cdot 100^{-1}$ de $\mathrm{Mn}$ e 12,93 a $17,84 \mathrm{mg} \cdot 100^{-1}$, pode-se verificar que são coerentes, entretanto são superiores aos obtidos por Yamada et al. (2003), que foram de 6,97 a 10,50 mg. $\mathrm{Kg}^{-1}$ de $\mathrm{Cu}, 18,43$ a 24,83mg. $\mathrm{Kg}^{-1}$ de $\mathrm{Mn}, 37,80$ a 42,33mg. $\mathrm{Kg}^{-1}$ de $\mathrm{Zn}$, em quatro cultivares de soja (IAC PL1, IAC 22, IAC 8-2 e

IAC 15-2).

Ao se analisar os dados obtidos para os micronutrientes (Tabela 3) pode-se observar que a soja apresenta quantidade razoável de cobre $(\mathrm{Cu})$, ferro $(\mathrm{Fe})$ e zinco $(\mathrm{Zn})$, fator este importante em termos de alimentação humana e animal. Comparando os valores, aqui obtidos, com os obtidos por Yamada et al. (2003), que foram 6,77 a 10,50mg/Kg de $\mathrm{Cu}, 37,80$ a 42,33mg/Kg de 
$\mathrm{Zn}$ e 18,43 a $24,83 \mathrm{mg} / \mathrm{Kg}$ de $\mathrm{Mn}$, verifica-se que são inferiores com exceção dos valores encontrados para cobre.

\section{CONCLUSÃO}

Pelos resultados obtidos pode-se concluir que, as cultivares de soja aqui estudada, apresentaram alto teores em óleo e baixo teor de proteína, comparado com os valores citados na literatura. No geral, pode-se concluir que, através dos resultados obtidos neste estudo, que as cultivares de soja tem potencial para utilização na alimentação humana ou animal, e que com relação ao teor de óleo, todas as cultivares são promissoras para a indústria de extração de óleo.

\section{REFERÊNCIAS}

AGRIANUAL 2015. Anuário Estatístico da Agricultura Brasileira. São Paulo: FNP Consultoria \& Agroinformativos, 2015. p. 406-427.

ALBRECHT, P.et al. Teores de óleo, proteínas e produtividade de soja em função da antecipação da semeadura na região oeste do Paraná. Bragantia, Campinas, v.67, n.4, p.865-873. Dez. 2008.

ALMEIDA, L. A.et al. Melhoramento da soja para regiões de baixas latitudes. In: QUEIRÓZ M. A; GOEDERT C. O; RAMOS S. R. R. Recursos genéticos e melhoramento de plantas para o Nordeste brasileiro. Petrolina-PE: Embrapa Semi-Árido/Brasília-DF: Embrapa Recursos Genéticos e Biotecnologia. Disponível em: <http://www.cpatsa.embrapa.br/catalogo/livrorg/ sojamelhoramento.pdf>. Acessado em: 10 de jun. de 2016.

CAVALCANTE, A.K.; SOUSA, L.B.de. Determinação e avaliação do teor de óleo em sementes de soja pelos métodos de ressonância magnética nuclear e soxhlet. Biosci. J. Uberlândia, v. 27 , n. 1, p.8-15, fev. 2011.

CIABOTTI, S.et al. Avaliações químicas e bioquímicas dos grãos, extratos e tofus de soja comum e de soja livre de lipoxigenase. Ciência e Agrotecnologia, Lavras, v. 30, n. 5, p. 920 929, set./out. 2006.

DEMBOGURSKI, N.M.S.S. Determinação do preço da soja para trituração e obtenção do óleo com base na qualidade do grão. 2003. 86f. Dissertação (Mestrado em Modelagem Matemática)- Universidade Regional do Noroeste do Estado do Rio Grande do Sul. Ijuí.

EMBRAPA. EMPRESA BRASILEIRA DE PESQUISA AGROPECUÁRIA. Soja na Alimentação - Composição Química e Propriedades. Disponível em: <http://www.cnpso.embrapa.br/soja_alimentacao/index.php?pagina=23>. Acesso em: $03 \mathrm{fev}$ 2016.

IAL-INSTITUTO ADOLFO LUTZ. Normas analíticas: método químico e físico para análise de alimentos. 4. ed. São Paulo: IAL, 2008. p.1020 (on line). 
KAMIKAZE N. K. K.; NOVACKI C.; ZAIA D. A. M. Determinação de proteínas e lipídeos totais, umidade, cinzas, macro $(\mathrm{Ca}, \mathrm{Mg}, \mathrm{K})$ e micro elementos ( $\mathrm{Fe}, \mathrm{Cu}, \mathrm{Mn}, \mathrm{Zn}$ ) em cultivares de soja [Glycine max (L.) Merrill] não-transgênicas e transgênicas.. Ciências Exatas e

Tecnológicas. Londrina, v, 27, n. 2, p. 175-181. Jun./dez. 2006.

MALAVOLTA, E.; VITTI, G.C.; OLIVEIRA, S.A.de. Avaliação do estado nutricional das plantas - princípios e aplicações. 2. ed. Piracicaba: Associação Brasileira para Pesquisa da Potassa e do fosfato, 1997. 319p.

MAPA MINISTÉRIO DA AGRICULTURA, PECUÁRIA E ABASTECIMENTO. Soja. Disponível em: <http://www.agricultura.gov.br/vegetal/culturas/soja>. Acesso em: 09 jun. 2016.

MAREGA FILHO, M.et al.. Relationships among oil content, protein content and seed size in soybeans. Brazilian Archives of Biology and Technology, Curitiba, v.44, n.1, p.23-32, 2001.

MARTIN, T.Net al.. Tamanho ótimo de parcelas e número e repetições em soja. Ciência Rural, Santa Maria, v.35, n.2, p.276-271, abril 2005.

MORAES, R. M. A.et al.. Caracterização bioquímica de linhagens de soja com alto teor de proteína. Pesquisa Agropecuária Brasileira, Brasília, v. 41, n. 5, p.725-729, maio 2006.

NEPA/UNICAMP - NÚCLEO DE ESTUDOS E PESQUISAS EM ALIMENTAÇÃO. UNIVERSIDADE ESTADUAL DE CAMPINAS. Tabela Brasileira De Composição De Alimentos. NEPA-UNICAMP. 4.ed. rev.e ampl. Campinas: UNICAMP, 2011. 161p. (on-line).

PANERO, G. S.et al.. Determinação de K, Ca, Mg, Fe, Mn e Zn em 5 cultivares de soja do estado de Roraima por ICP- OES. IN: CONGRESSO BRASILEIRO DE QUÍMICA,47, 200, ABQRN: Natal, 17 a 21 de set. 2007.

POYSA, V.; WOODROW, L.; YU, K. Effect of soy protein subunit composition on tofu quality. Food Res. Int., v.39, n.3, p. 309-317, set. 2006.

SARRUGE, J. R.; HAAG, H. P. Analises químicas em plantas. Piracicaba: ESALQ/USP, 1974. $56 \mathrm{p}$.

SBARDELOTTO, A.; LEANDRO, G.V.. Escolha de cultivares de soja com base na composição química dos grãos como perspectiva para maximização dos lucros nas indústrias processadoras. Revista Ciência Rural, Santa Maria, p.614-619, jun. 2008.

SILVA, D. J.; QUEIROZ. A. C. Análise de alimentos: métodos químicos e biológicos. 3.ed. Viçosa, MG: Editora UFV, 2002. 165p.

SILVA, F.A.S. ASSISTAT: Versão 7.7 beta. Disponível em:< http://www.assistat.com/> . Acessado em: 20 nov. 2015.

VIEIRA, C.R.; CABRAL, L.C.; PAULA, A.C.O.de. Composição centesimal e conteúdo de aminoácidos, ácidos graxos e minerais de seis cultivares de soja destinadas à alimentação humana. Pesquisa Agropecuária Brasileira, Brasília, v. 34, n. 7, p.1267-1283, jul. 1999.

YAMADA, L. T. P.et al.. Composição química e conteúdo de ferro solúvel em soja [Glycine max (L.) Merrill]. Ciência e Agrotecnologia, Lavras, v. 27, n. 2, p.406-413, mar. 2006. 